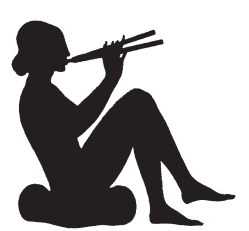

\title{
Turisme i patrimoni, una oportunitat
}

\footnotetext{
atalunya és des de fa anys la comunitat de l'Estat espanyol amb una major indústria turística. Actualment aquesta activitat suposa el I $2 \%$ del PIB del nostre país. Tradicionalment el turisme ha estat associat al model de sol i platja, però també s'ha anat diversificant amb altres propostes, com ara el turisme rural a zones de l'interior i sobretot el turisme cultural. L'any 1908, Barcelona va iniciar, amb la Sociedad de Atracción de Forasteros, una política de promoció de la ciutat que l'alcalde Porcioles va continuar amb el model de la Ciutat de Fires i Congressos. Però és a partir de l'èxit de la cita olímpica de 1992 que Barcelona ha passat a ser la tercera destinació del continent, un veritable referent. El 20 I I hem rebut 7.450 .000 visitants, amb un augment -en plena crisi- del 4,4 \% respecte de l'any anterior. Ha estat un cas d'èxit excepcional, en gran part imprevist, i segurament encara poc assumit socialment amb totes les seves conseqüències. Algunes coses s'han fet bé: el consorci publicoprivat Turisme de Barcelona - creat el 1993 - és molt actiu i ofereix una bona plataforma de promoció de la ciutat. Iniciativa seva va ser el Bus Turístic - un altre èxit-, que altres ciutats han imitat. El govern municipal anterior va promoure la redacció del Pla estratègic de turisme de la ciutat de Barcelona 2015, amb suggeriments molt valuosos. Segurament el caràcter hospitalari dels seus ciutadans, la imatge de ciutat oberta, tolerant, socialment cohesionada, oberta al Mediterrani i segura (encara que aquí hi ha problemes en relació amb els turistes) són elements que pesen, i molt. Però el que porta riuades de gent a Barcelona són els seus monuments i, especialment, les obres de Gaudí. El lloc més visitat de la ciutat va ser la Sagrada Família, amb 2.300.000 entrades el 2010, que van generar uns 30 milions d'euros, els quals - exempts d'impostos - es van reinvertir en la continuació de les obres. La Pedrera va acollir el mateix any un milió de visites i va generar uns is milions d'euros, i la casa Batlló
} 
va tenir 673.000 entrades. Del parc Güell, com que és d'ús públic, no en tenim xifres, encara que la Casa Museu Gaudí va ser visitada per 4I 2.000 persones. També els museus monogràfics dedicats a Picasso, Miró i Dalí (l'any 20 Io els museus Dalí van rebre I.330.000 visitants, 88 r.000 dels quals corresponen al Teatre-Museu de Figueres) esdevenen fites destacades en els itineraris turístics més massius. Gaudí és un nom d'abast internacional, segurament més conegut que la mateixa ciutat i potser només una mica menys que el Futbol Club Barcelona, que és una marca absolutament universal, com ho demostra el fet que el seu museu sigui el més visitat de la ciutat.

Els turistes passen una mitjana de dues o tres nits a Barcelona. Si volem que tornin, que aquestes estades s'allarguin i que abastin amb més força altres indrets del país, el repte és ampliar els itineraris culturals, fer que altres obres de Gaudí entrin en el circuit, juntament amb altres noms, com per exemple Lluís Domènech i Montaner, amb el Palau de la Música, l'Hospital de Sant Pau, l'Institut Pere Mata o la casa Navàs a Reus; Josep Puig i Cadafalch o Josep Maria Jujol a Sant Joan Despí i a les comarques de Tarragona. En aquest punt no hi ha cap mena de previsió ni d'estratègia. Cada institució propietària dels monuments fa el que li sembla i no hi ha una coordinació en l'explicació i la gestió de la informació. Si volem un turisme de qualitat, que no necessàriament vol dir només un turisme d'alt poder adquisitiu, hem de promocionar la Barcelona i la Catalunya monumental, i al mateix temps cal redirigir els turistes de l'oci més convencional cap a les noves fórmules de consum cultural.

Els estudiosos del patrimoni i els historiadors de l'art hem estat massa d'esquena al fenomen del turisme. No hem estat prou atents a la formació dels futurs gestors del turisme cultural i no hem sabut promoure una formació específica de grau i de postgrau amb aquest perfil. Tampoc no ens hem preocupat de proposar a les diverses administracions $\mathrm{i}$ a les empreses opcions renovadores d'explotació sostenible dels seus actius monumentals i patrimonials. Les greus dificultats financeres actuals de les universitats, dels centres de recerca, dels museus i d'altres centres patrimonials segurament no són conjunturals. El seu abast i la seva durada ens són desconeguts, però el que és poc raonable és no fer res i limitar-se a esperar temps millors. Els historiadors de l'art tenim un coneixement de gran valor cultural que també hauria d'esdevenir un valor de gran impacte econòmic i social. La nostra responsabilitat és inventar formes per transferir aquest coneixement a la societat $i$ donar sortida i utilitat a un patrimoni que té alguns elements de primer nivell internacional $\mathrm{i}$ amb un ampli reconeixement.

Hem de fer servir els enormes beneficis del turisme - ara potser massa focalitzat en unes quantes fites estrella- per sostenir i estimular la investigació històrica i artística sobre el conjunt del nostre patrimoni. En el camp de la divulgació és valuosa la feina feta per l'Ajuntament de Barcelona mitjançant l'Institut del Paisatge Urbà, que ha promogut una xarxa europea de ciutats amb patrimoni modernista $\mathrm{i}$ ha elaborat materials de difusió. Cal que altres ciutats $\mathrm{i}$ comarques facin seu i adaptin aquest model amb l'ajuda dels histo- 
riadors i d'altres professionals de la gestió patrimonial i turística. En aquest sentit, hem de valorar positivament algunes iniciatives de la Generalitat de Catalunya, gestionades pel Servei de Turisme del Departament d'Empresa i Ocupació, el Servei del Departament de Cultura i l'Agència Catalana de Turisme (un organisme publicoprivat de promoció turística), com ara la creació de les rutes nacionals de Catalunya (Pirineu comtal, camí de Sant Jaume) o la ruta del Cister (Poblet, Santes Creus, Vallbona de les Monges). Tanmateix, la màxima institució de govern del país hauria de fer un esforç suplementari en la tasca de dinamitzar el turisme cultural i dissenyar una política a l'alçada de les possibilitats reals del nostre patrimoni. Però aquesta tasca de promoció del turisme i divulgació cultural no pot estar al marge i ser independent de la recerca universitària, que hauria de sostenir-se i alhora vincular-se amb la gestió patrimonial; en definitiva, haurien de ser dues cares d'una mateixa moneda. No tenim a Catalunya un gran centre de recerca en història de l'art. Aquesta és una mancança molt greu. No s'entén que el turisme i el patrimoni siguin un element de progrés econòmic excepcional $i$ ens falti un instrument de coneixement científic i de projecció internacional d'aquest. D'altra banda, resta per debatre una qüestió essencial: l'encaix exacte de la nostra disciplina i dels nostres ja molt nombrosos titulats en el panorama de la difusió turística del patrimoni. 